\title{
In-Situ Fabrication of ZrB2-ZrC-SiCnws Hybrid Nanopowders With Tunable Morphologies of SiCnws
}

Changqing Liu ( $\sim$ liu280097311@163.com )

Shaanxi University of Science \&Technology

Xiaoxiao Yuan

Shaanxi University of Science \&Technology

Wanting Wang

Shaanxi University of Science \&Technology

Hulin Liu

Shaanxi University of Science \&Technology

Chengxin Li

Xi'an Jiaotong University

Heng Wu

cGongyi Van-Re Yihui Composite Material CO.

Xianghui Hou

The University of Nottingham

\section{Research Article}

Keywords: SiCnws, Morphologies, In-situ synthesis, ZrB2-ZrC, Nanopowder

Posted Date: July 27th, 2021

DOl: https://doi.org/10.21203/rs.3.rs-738256/v1

License: (9) (i) This work is licensed under a Creative Commons Attribution 4.0 International License.

Read Full License 


\section{In-situ fabrication of $\mathrm{ZrB}_{2}$-ZrC-SiCnws hybrid nanopowders with tunable morphologies of SiCnws}

Changqing Liu ${ }^{\mathrm{a}}$,, Xiaoxiao Yuan ${ }^{\mathrm{a}}$, Wanting Wang ${ }^{\mathrm{a}}$, Hulin Liu ${ }^{\mathrm{a}}$, Chengxin $\mathrm{Li}^{\mathrm{b}}$, Heng $\mathrm{Wu}^{\mathrm{c}, *}$, Xianghui Hou ${ }^{\mathrm{d}, *}$

${ }^{a}$ School of Material Science and Engineering, Shaanxi Key Laboratory of Green Preparation and Functionalization for Inorganic Materials, Shaanxi University of Science \&Technology, Xi'an, Shaanxi 710021, China

${ }^{\mathrm{b}}$ State Key Laboratory for Mechanical Behavior of Materials, School of Materials Science and Engineering, Xi'an Jiaotong University, Xi'an, Shaanxi 710049, China

${ }^{c}$ Gongyi Van-Re Yihui Composite Material CO., LTD, Gongyi 451261, China

${ }^{\mathrm{d} A d v a n c e d}$ Materials Research Group, The University of Nottingham, Nottingham, NG7 2RD, UK

*Corresponding authors

Changqing Liuｌiu280097311@163.com (C.Q. Liu)

Heng Wu $\quad$ wuheng@van-research.cn (H. Wu)

Xianghui Hou Xianghui.Hou@ nottingham.ac.uk (X.H. Hou) 


\begin{abstract}
s
$\mathrm{SiC}$ nanowires (SiCnws) with different morphologies have great potential for the reinforcement of ceramic materials. But it is a big challenge in the in-situ synthesis of SiCnws in the ceramic powders which is critical to ensure high reinforcing effects. For the reinforcement of $\mathrm{ZrB}_{2}-\mathrm{ZrC}$ composites, a simple method is developed to in-situ fabricate $\mathrm{SiCnws}$ with various morphologies in nano-sized $\mathrm{ZrB}_{2}-\mathrm{ZrC}$ powders through pyrolyzing $\mathrm{ZrB}_{2}-\mathrm{ZrC}-\mathrm{SiC}$ gel precursors. The prepared $\mathrm{ZrB}_{2}-\mathrm{ZrC}$ ceramic powders have mean diameter of about $100 \mathrm{~nm}$ with uniformly distributed SiCnw in morphologies of nanocylider, bead-like, bamboo-shape with tunable nodes, chain-like and hexagonal prisms were prepared by optimizing the preparation process. Moreover, the SiCnws were in a diameter of ranging from 100 to $400 \mathrm{~nm}$, while the length was controlled from tens to hundreds of microns. The generation of $\mathrm{ZrB}_{2} / \mathrm{ZrC}$ can determine the formation of SiCnws with specific morphologies by producing $\mathrm{CO}$ gas to affect the local supersaturation of the $\mathrm{SiO}$ and $\mathrm{CO}$ vapors. The study provides an opportunity for fabricating $\mathrm{SiCnw}$ reinforced ceramic materials with enhanced strengthening effect and also overcome its critical fabrication process.
\end{abstract}

Keywords: SiCnws, Morphologies, In-situ synthesis, $\mathrm{ZrB}_{2}-\mathrm{ZrC}$, Nanopowder, 


\section{Introduction}

As members of ultra-high-temperature ceramics (UHTCs), $\mathrm{ZrB}_{2}-\mathrm{ZrC}$ ceramics have been considered as one of the most excellent materials for high-temperature applications because of their chemical inertness, high thermal and electrical conductivity, and super thermal shock resistance, etc [1-3]. However, their wide applications in harsh environment are still restricted owe to the low oxidation resistance, intrinsic brittleness, and poor sinterability [4-7].

Recently, $\mathrm{ZrB}_{2}-\mathrm{ZrC}$ ceramic materials with the addition of $\mathrm{SiC}$ have demonstrated improved densification behavior, enhanced mechanical properties and excellent oxidation and ablation resistance at high temperatures [8-13], since the incorporated $\mathrm{SiC}$ phase could effectively restrain the crystallite growth, promote the sinterability, and form $\mathrm{ZrB}_{2}-\mathrm{ZrC}-\mathrm{SiC}$ composites with higher eutectic temperature and higher hardness [14-16]. Moreover, SiC nanowires (SiCnws) are used extensively as effective reinforcements with a larger aspect ratio, better strength and elasticity, to enhance the flexural strength and the fracture toughness of ceramic materials [17-20].

As the starting materials to prepare bulk ceramics, ultrafine powders with controlled compositions and microstructures have drawn much attention. $\mathrm{ZrB}_{2}-\mathrm{ZrC}$ ceramic powders with uniformly distributed SiCnws are critical for the fabrication of $\mathrm{ZrB}_{2}-\mathrm{ZrC}-\mathrm{SiC}$ composites. However, it is difficult to disperse SiCnws homogenously into ceramic powders through ball-milling or other mixing approaches, which would affect the mechanical performance of the prepared composites [21]. To solve this problem, in-situ growth of SiCnws in ceramics is believed to be an effective solution [22-25], in which the synchronous growth of the nanowires and ceramic components can be well achieved.

Furthermore, SiCnws with special morphologies have shown great potential for the reinforcement of structural materials. It is reported that SiCnws with necklace and bamboo morphology could offer enhanced strengthening effect compared with common SiCnws, due to the mechanical interlocking with the matrix [26]. Although great efforts have been devoted to the fabrication of SiCnws with different morphologies, including diameter-fluctuated (such as necklace-like and 
bamboo-shaped) [27,28], twinned [29], nanodishes or nanorods [30] etc. There is no report concerning the in-situ synthesis of SiCnws with specific morphologies in the ceramic powders. And it is still a great challenge to fabricate $\mathrm{ZrB}_{2}-\mathrm{ZrC}$-SiCnws hybrid powders, due to the difficulty in the control of SiCnws growth during the prepartion of $\mathrm{ZrB}_{2}-\mathrm{ZrC}-\mathrm{SiC}$ ceramics, especially in a ternary system with sophisticated gas saturation variation.

Moreover, the sinterability of ceramics is determined by the size and distribution of the starting powders. Usually better refinement and uniformity of the particles are desirable for a better sinterability [31.32]. Recent study suggests that an enormous improvements in terms of optical, mechanical and electrical properties can be acquired through reducing the component size towards nanoscale in the composite materials[33,34]. Sol-gel method is a commonly used approach for the preparation of a wide range of nanocomposites, such as oxide powders, and carbides, boride and nitride UHTCs [35,36], due to the advantages of high purity and homogeneity of the ceramic elements at the molecular level, which may also reduce the particle size and the formation temperature of aimed ceramic phases [37-39].

Therefore, in the present work, $\mathrm{ZrB}_{2}-\mathrm{ZrC}-\mathrm{SiC}$ nanocomposite powders with evenly distributed SiCnws of various specific morphologies in large amount were obtained via a simple sol-gel method, i.e. pyrolysis of as-prepared $\mathrm{ZrB}_{2}-\mathrm{ZrC}$-SiC gel precursor. The formation mechanism of $\mathrm{ZrB}_{2}-\mathrm{ZrC}-\mathrm{SiCnw}$ and the growth behavior of SiCnws were investigated, together with the pyrolysis process parameters, such as the heat-treatment temperature and holding time as well as the silicon source in feed. The successful preparation of the $\mathrm{ZrB}_{2}-\mathrm{ZrC}-\mathrm{SiCnw}$ powders provides a new opportunity for the preparation of high-performance SiCnws-reinforced ceramic materials with desirable nanostructures.

\section{Experimental Section}

In our work, the $\mathrm{ZrB}_{2}-\mathrm{ZrC}-\mathrm{SiC}$ sol precursor was obtained by fully mixing zirconium solution, boron-ethanol solution, silicon-ethanol solution and glucose-water solution. And then, the $\mathrm{ZrB}_{2}-\mathrm{ZrC}-\mathrm{SiC}$ sol precursor was dried and used for the 
subsequent heat treatment. To be specific, the zirconium solution was prepared by dissolving $\mathrm{ZrOCl}_{2} \cdot 8 \mathrm{H}_{2} \mathrm{O}(0.01 \mathrm{~mol})$ in ethanol $(20 \mathrm{~mL})$ and $\mathrm{H}_{2} \mathrm{O}_{2}(2 \mathrm{~mL})$. The boron-ethanol solution was prepared by dissolving $\mathrm{H}_{3} \mathrm{BO}_{3}(0.02 \mathrm{~mol})$ and PEG-600 $(0.05 \mathrm{~mL})$ in boiling ethanol $(50 \mathrm{~mL})$. A series of silicon-ethanol solutions were obtained by mixing various TEOS content in ethanol $(20 \mathrm{~mL})$. While, the glucose-water solution was prepared by dissolving glucose $(0.068 \mathrm{~mol})$ in distilled water $(10 \mathrm{~mL})$.

In order to produce SiCnws with different microstructures, precursors, heat-treated temperature and holding times were carefully controlled. A lower processing temperature of $1500{ }^{\circ} \mathrm{C}$ and a holding time of $2 \mathrm{~h}$ as well as improving the content of silicon in the gel precursor, i.e., the silicon/zirconium molar ratio $(\mathrm{n}(\mathrm{Si}) / \mathrm{n}(\mathrm{Zr}))$ in the precursor was varied from $6,8,10,12,14$ to 16 , were applied in our work. In comparison, the holding time varied from 1 to $4 \mathrm{~h}$, and the temperature was set at 1300 and $1400{ }^{\circ} \mathrm{C}$. Moreover, the reaction temperature was increased to $1600{ }^{\circ} \mathrm{C}$ and the holding time was kept at $2 \mathrm{~h}$ with a silicon/zirconium molar ratio of 12. The preparation process is illustrated in Figure 1. As illustrated, with an $n(\mathrm{Si}) / \mathrm{n}(\mathrm{Zr})$ value of 6-10, SiCnws in nanocylinders shape were formed by heat-treating the precursor at $1500{ }^{\circ} \mathrm{C}$ for $2 \mathrm{~h}$. By increasing the $\mathrm{n}(\mathrm{Si}) / \mathrm{n}(\mathrm{Zr})$ value to 12 , SiCnws with uneven diameters showing bead-like morphology were formed. Futher increasing the silicon source in the precursor $(\mathrm{n}(\mathrm{Si}) / \mathrm{n}(\mathrm{Zr})$ value of 14-16), the morphologies of the produced SiCnws would be in bamboo shape with varying nodes. For a longer holding time of $4 \mathrm{~h}$, the SiCnws finally grew into hexagonal prism nanocylinders. At high temperature $\left(1600^{\circ} \mathrm{C}\right)$, the SiCnws in chain-like morphologies were obtained.

Phases of the samples were identified by X-Ray diffraction (XRD, Bruker, Germany). Crystalline sizes of each phase were calculated by the Scherrer equation. Contents of each phase were obtained by the Rietveld method. The structure of the ceramic samples was investigated by high-resolution transmission electron microscope (HRTEM, FEI Tecnai G2 F20 STWIN). Raman spectra were collected on a Raman spectrometer (Raman, Renishaw, UK) with its excitation wavelength at 514 nm. Separation and analysis of the Raman peaks were conducted using the peak 
analyzer function of origin software.

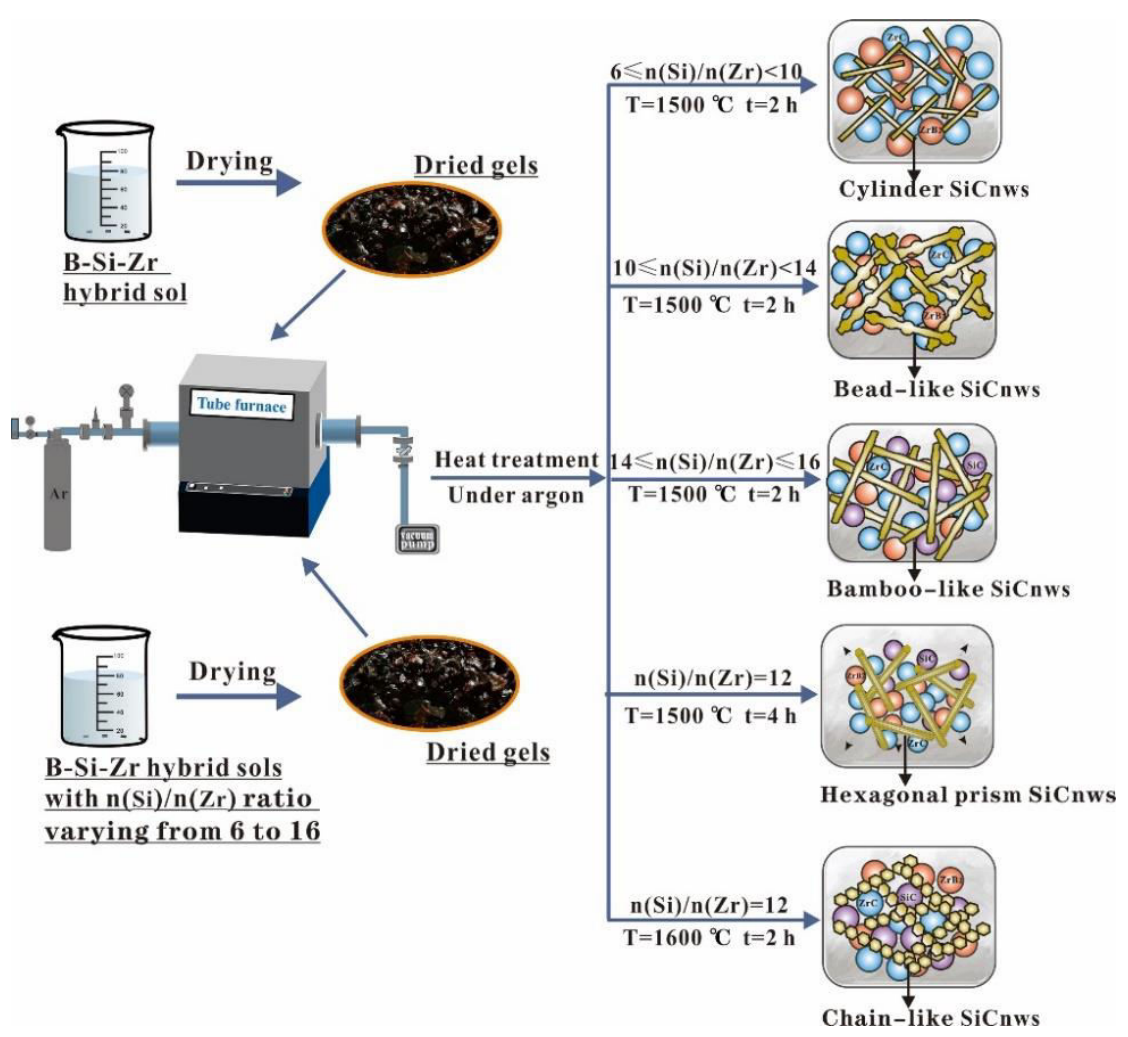

Figure 1. Synthesis procedure of $\mathrm{ZrB}_{2}-\mathrm{ZrC}-\mathrm{SiCnws}$ with different microstructures

\section{Results and discussion}

\subsection{Impact of heat-treated temperature on the formation of the products}

Fig. 2 shows the XRD results of products obtained at 1300, 1400, 1500 and $1600{ }^{\circ} \mathrm{C}$. At $1300{ }^{\circ} \mathrm{C}$, only $\mathrm{SiO}_{2}$ and $\mathrm{ZrO}_{2}$ were observed, indicating that the temperature was not high enough to initiate the carbo/boronthermal reduction reactions to produce $\mathrm{ZrB}_{2}, \mathrm{ZrC}$ and $\mathrm{SiC}$. As the temperature was increased to $1400{ }^{\circ} \mathrm{C}$, $\mathrm{SiO}_{2}$ and $\mathrm{ZrO}_{2}$ remained the major phase, and a small amount of $\mathrm{SiC}$ was observed, indicating the onset temperature for $\mathrm{SiC}$ formation. At $1500{ }^{\circ} \mathrm{C}$, a XRD pattern containing $\mathrm{ZrB}_{2}, \mathrm{ZrC}$ and $\mathrm{SiC}$ was obtained. The peaks of $\mathrm{SiC}$ can be assigned to the (101), (006) and (108) reflections of 6H-SiC, among which and the (006) diffraction peak are the strongest, indicating that SiCnws mainly grew along the direction of [001]. Besides $\mathrm{SiC}, \mathrm{ZrB}_{2}$ and $\mathrm{ZrC}$ phases, no other phases were detected, which suggested that the carbo/boronthermal reduction reactions were complete at $1500{ }^{\circ} \mathrm{C}$. As the temperature was raised to $1600{ }^{\circ} \mathrm{C}$, the intensities of $\mathrm{SiC}$ diffraction peaks 
increased, suggesting that higher temperature may favour the generation of $\mathrm{SiC}$ by reducing the loss of Si-related gaseous reactants.

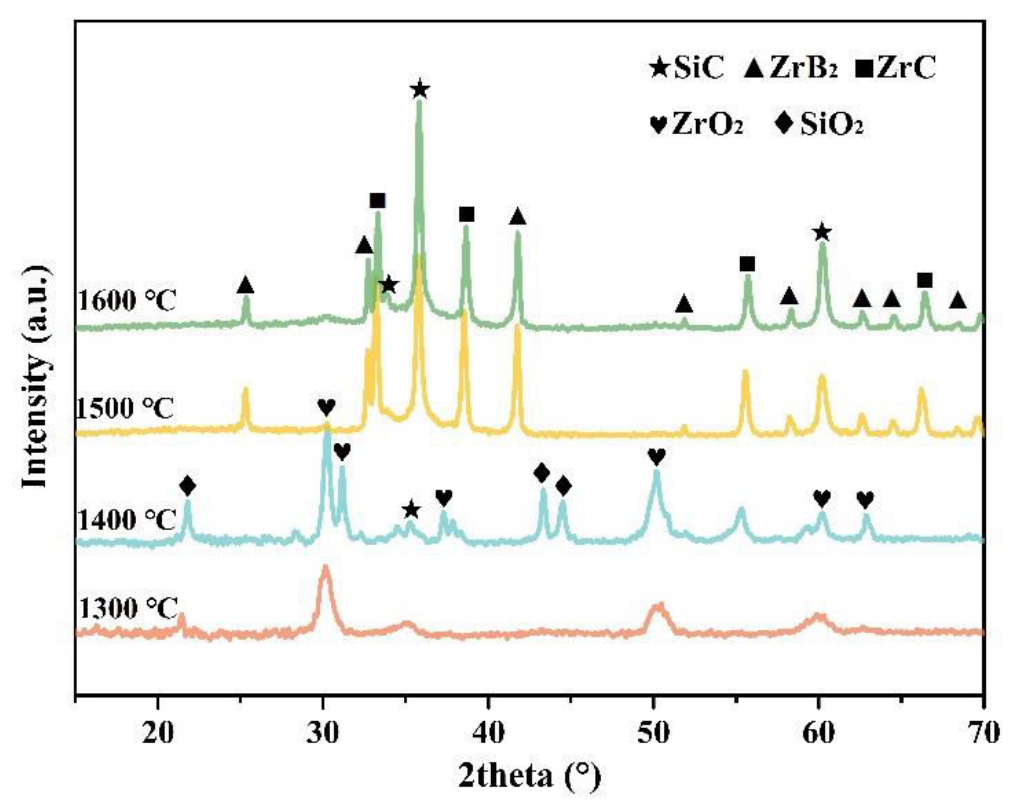

Figure 2. XRD results of products obtained at 1300, 1400, 1500 and $1600{ }^{\circ} \mathrm{C}$

Fig. 3 displayes the SEM results of products obtained at 1300, 1400, 1500 and $1600{ }^{\circ} \mathrm{C}$, respectively. Since the temperature of $1300{ }^{\circ} \mathrm{C}$ was not high enough to initiate carbo/boronthermal reduction reactions, a porous product with many micro-cracks was observed (Fig. 3a). Meanwhile, without the release of SiO/CO gases, there was no SiCnw grown in the product. After heat-treated at $1400{ }^{\circ} \mathrm{C}$ (Fig. 3b), the porous products remained, but dropwise projections appeared on its surface, which was ascribed to $\mathrm{SiO}_{2}$ based on the result of EDS. Meanwhile, large quantities of wire-like SiCnws with diameters around $200 \mathrm{~nm}$ and lengths longer than $100 \mathrm{um}$ appeared. Combined with the XRD analysis, $\mathrm{SiC}$ was formed at $1400{ }^{\circ} \mathrm{C}$, during which the generated $\mathrm{SiO} / \mathrm{CO}$ gases provided the gas saturation for the continuous growth of one-dimensional SiC. And also, due to the low and periodical fluctuating gas supersaturation, the periodically fluctuated diameter of nanowires were produced. Hence, uniform and thin SiCnws in bamboo-like shape were achieved at a relatively stable growth rate. Further increasing the temperature to $1500{ }^{\circ} \mathrm{C}$ (Fig. 3c), a large quantity of SiCnws together with fine ceramic particles were obtained. The SEM image reveals the formation of fine ceramic particles in a size of about $150 \mathrm{~nm}$ with irregular appearance. The diameter of SiCnw varied in the range of 100-400 nm. The 
length of SiCnws was over tens of microns. Moreover, unevenly distributed bamboo joints with variations in thickness were observed. At this temperature, reactions between the oxides and the carbon happened vigorously, accompanied with the generation of large quantity of $\mathrm{SiO} / \mathrm{CO}$ gases and the formation of $\mathrm{ZrB}_{2}-\mathrm{ZrC}-\mathrm{SiC}$ phases. Because of the higher temperature and higher amount of gases, a high gas supersaturation contributing to an enhanced deposition rate and growth rate of $\mathrm{SiC}$ was obtained. Large fluctuations of gas saturation resulting from the rapid gas consumption lead to the nonconstant diameter in a single SiCnw. Further heat-treated at $1600{ }^{\circ} \mathrm{C}$ (Fig. 3d), an increased gas concentration and accelaerated growth rate of $\mathrm{SiC}$ were achieved because of the increased temperature, accompanied by the formation of chain-like nanowires with lengths higher than $100 \mathrm{um}$ and diameter around $400 \mathrm{~nm}$. Meanwhile, the average size of ceramic particles was about $100 \mathrm{~nm}$.

Based on the above discussion, by improving the temperature from 1300 to $1600{ }^{\circ} \mathrm{C}$, the ceramic products were transformed from porous oxides into $\mathrm{ZrB}_{2}, \mathrm{ZrC}$ and $\mathrm{SiC}$ ceramics with $100 \mathrm{~nm}$ size. $1400{ }^{\circ} \mathrm{C}$ was high enough to provide the energy to grow one-dimensional SiCnws. The growth of SiCnws began at $1400{ }^{\circ} \mathrm{C}$, and with the increasing of temperature, the morphology of SiCnws evolved from bamboo-like shape (diameter around $150 \mathrm{~nm}$ ) into chain-like shape linked by polyhedra (diameter around $400 \mathrm{~nm}$ ). 


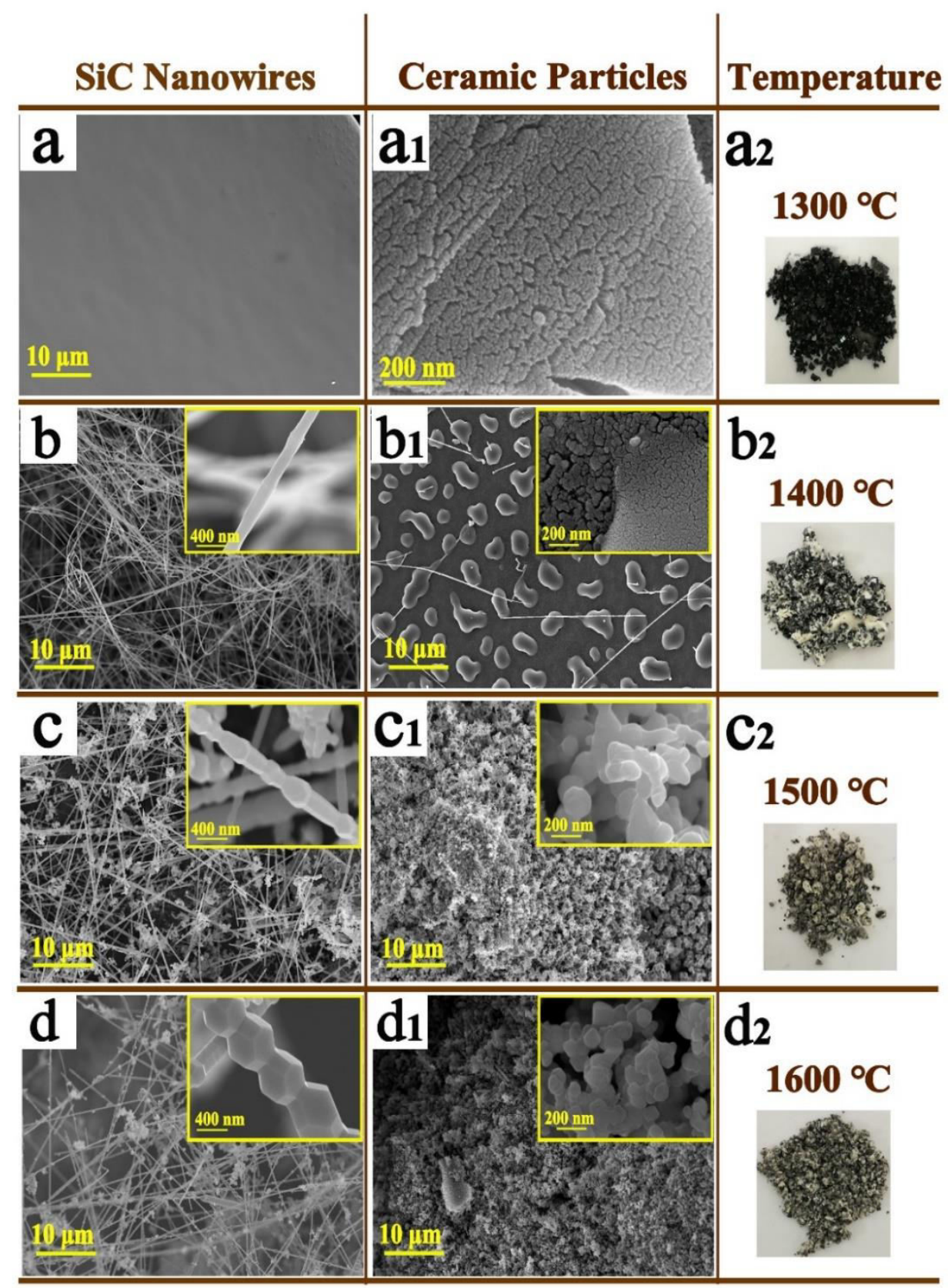

Figure 3. SEM results of products obtained at different temperatures

\subsection{Impact of holding time on the formation of the products}

Fig.4 demonstrates the XRD results of the products prepared at different holding times at $1500{ }^{\circ} \mathrm{C}$. After heat treatment at $1500{ }^{\circ} \mathrm{C}$ for $1 \mathrm{~h}$, only $\mathrm{ZrB}_{2}$ and $\mathrm{SiC}$ phases were detected, indicating that the reaction was not completed to produce $\mathrm{ZrC}$. Diffraction peaks assigned to $\mathrm{ZrC}$ appeared with extending holding time of $2 \mathrm{~h}$. With prolonged holding time, besides the sharped diffraction peaks and increased peak intensities, no other changes were observed from the XRD patterns. Based on the phase composition of the products in Fig.5a, the content of $\mathrm{SiC}, \mathrm{ZrB}_{2}$ and $\mathrm{ZrC}$ phases 
did not change significantly with extending the holding time from 2 to $4 \mathrm{~h}$, indicating that the reactions to produce the above phases were completed for two hours of holding time. When further increased the holding time, phase composition of the products kept unchanged, except for the improved crystallinity. Fig.5b shows the apparent crystal size of each phase in the products obtained from various holding times. It shows that with extending holding time, the crystal size of each ceramic phase tended to decrease.

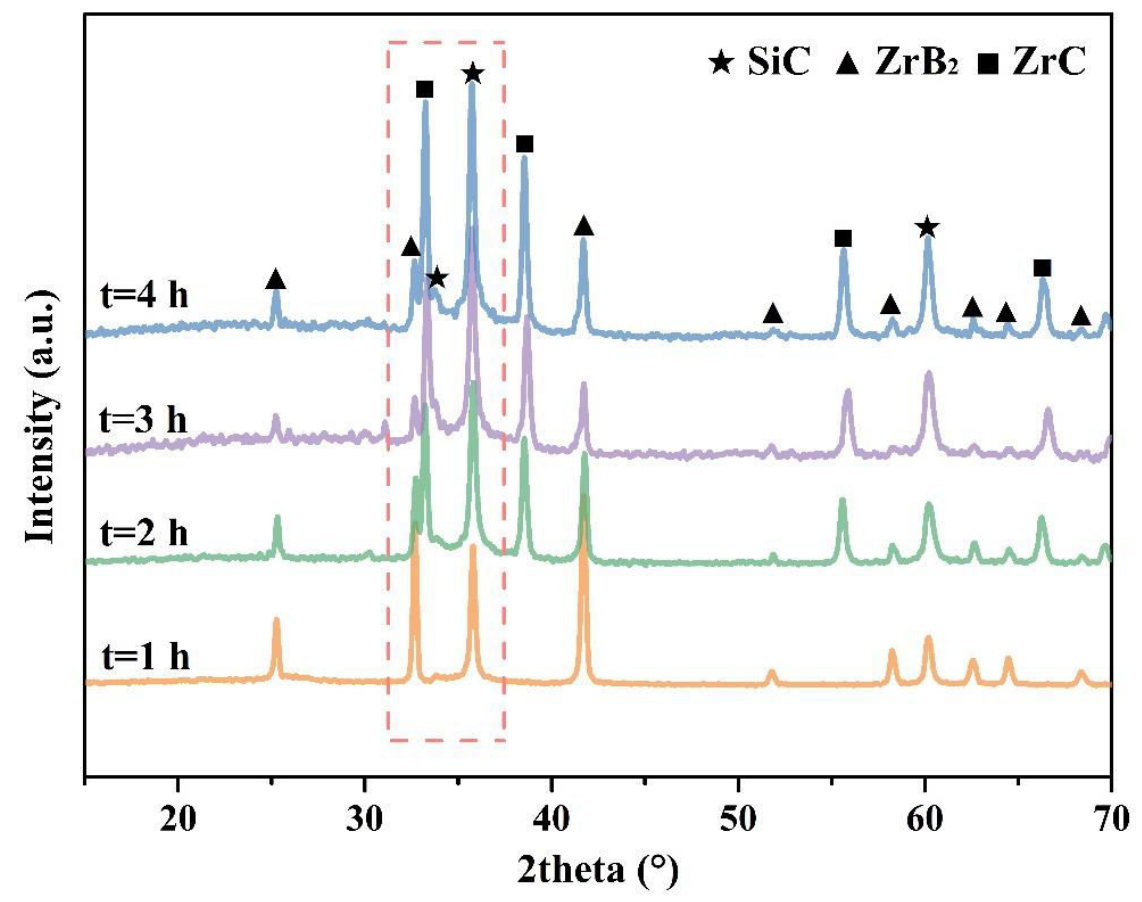

Figure 4. XRD results of the products with different holding times
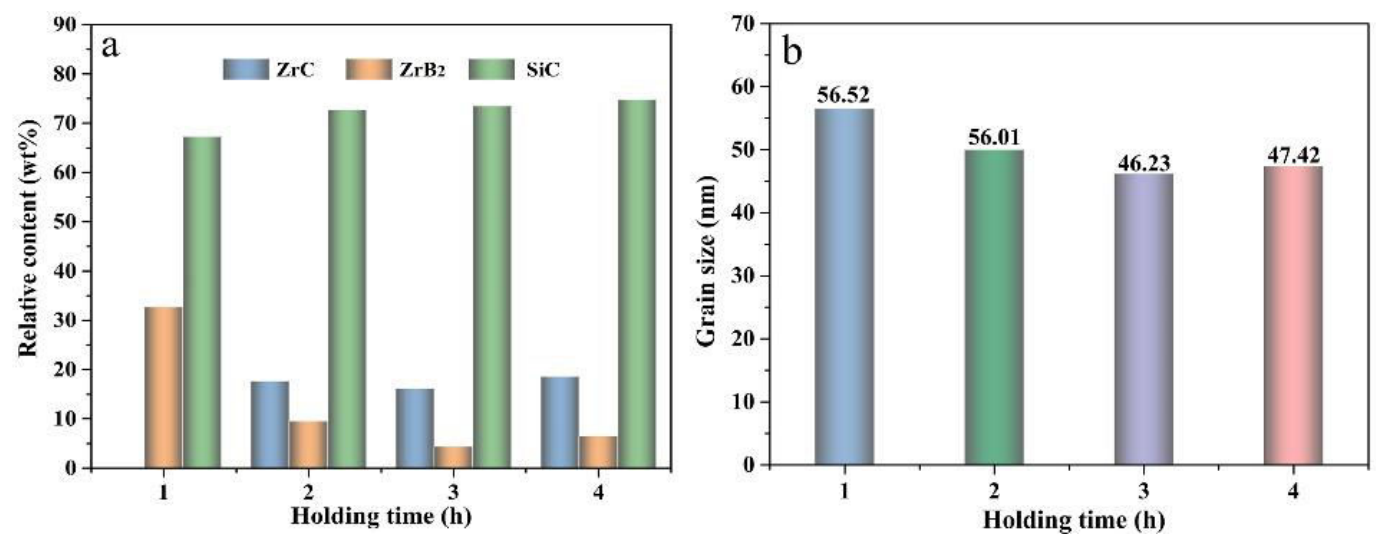

Figure 5. The content (a) and the crystal size (b) of key phases in the products with various holding times

Fig.6 displayes the SEM results of the products from the precursors with 
different holding times. After thermal treatment at $1500{ }^{\circ} \mathrm{C}$ for $1 \mathrm{~h}$, because of the short holding time, the reactions were not completed, and only a low concentration of reactant gases was produced. Under this condition, the growth of SiCnws was favoured, and a large quantity of long SiCnws was observed. Meanwhile, the ceramic particles mainly composed of cubic $\mathrm{ZrB}_{2}$ particles. With prolonged holding time of 2 $\mathrm{h}$, large amount of SiCnws with a length up to 100 microns were found to disperse uniformly in the ceramic products. Combined with the analysis of XRD, the carbo/boronthermal reduction reactions seemed to be completed with a holding time of $2 \mathrm{~h}$, during which the gas concentration reached its maximum. Due to the increase amount of reactant gases and high temperature, the energy of gas molecules, their migration and collision frequencies are increased, and a larger gas supersaturation was obtained. Since the nucleation is proportional to the supersaturation degree, a large amount of SiC crystals were formed. And then, with a relatively higher degree of gas supersaturation, a high nucleation and growth rate lead to the formation of large amount of SiCnws with uneven diameters and shorter lengths. With a holding time of $3 \mathrm{~h}$, a large amount of SiCnws were distributed in the product, showing smaller diameters and longer lengths. Compared to two hours of holding time, the particle size of ceramic powder was reduced. With the prolonging of holding time, the gas concentration was further diluted by the growth of large SiC crystals. The growth of SiCnws was maintained by a low but stable gas supplement, and reached lengths higher than $100 \mathrm{um}$. When holding at $1500{ }^{\circ} \mathrm{C}$ for $4 \mathrm{~h}$, only a few SiCnws was observed in the product. The uniform ceramics with an average size around 50nm were obtained. With an excessive holding time $(4 \mathrm{~h})$, the growth of SiCnws was strongly suppressed. The above analysis confirmed that the continuous growth of SiCnws was supported by a relatively low supersaturation $\sum$, which is controlled by the partial pressure of $\mathrm{SiO}$ and $\mathrm{CO}$ gases, i.e., $\sum=\mathrm{k} \cdot P_{\mathrm{SiO}} / P_{\mathrm{CO}} . \mathrm{k}$ represents the equilibrium constant of the reaction to form $\mathrm{SiC}$, i.e., $\mathrm{SiO}(\mathrm{g})+3 \mathrm{CO}(\mathrm{g})=\mathrm{SiC}(\mathrm{s})+$ $2 \mathrm{CO}_{2}(\mathrm{~g})$. When supersaturation exceeded the adaptable range, the $\mathrm{SiC}$ phase in the form of particles was favoured. Due to the over-consumption of gases through the generation of large $\mathrm{SiC}$ crystals during the holding period, the degree of gas 
supersaturation was to low to keep the growth of one-dimensional SiC. Therefore, just a small amount of SiCnws was formed under the over-reduced gas saturation.

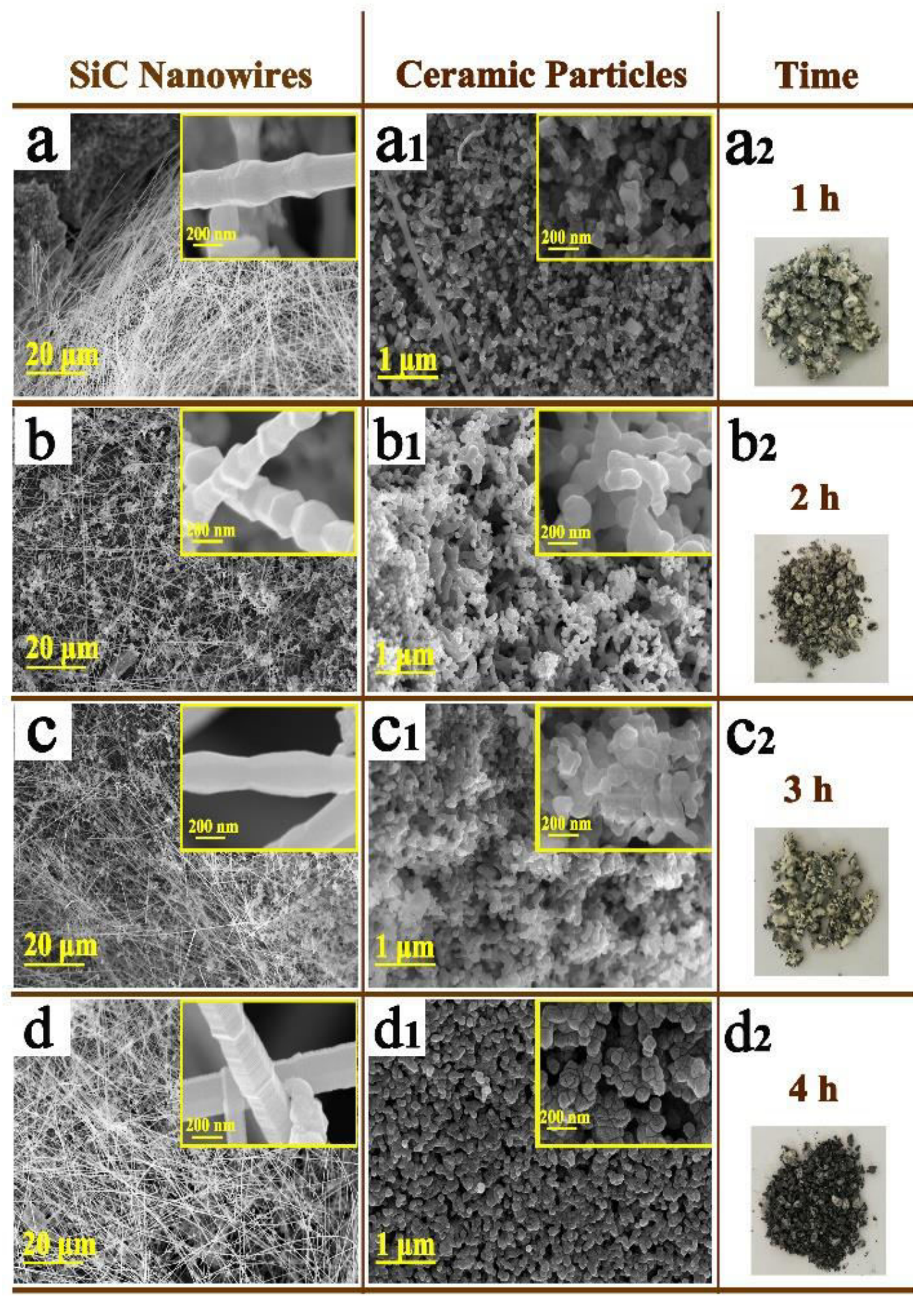

Figure 6. SEM results of the products from the precursors with different holding times

The reason for the morphological evolution of the SiCnws during the prolonging of holding times can be explained as follows. The shape of the grown 2D nuclear lay 
on the competition between the kinetic conditions and the minimization of surface and line energies [40]. With a low and fluctuating gas saturation, the growth of SiCnws in hexagonal and cylindrical shape grew competitively, forming this metastable shape of nanowires with holding time of one hour. Improving the holding time to $2 \mathrm{~h}$, the gas saturation increased dramatically, accompanied by an increase in growth rate, thus contributing to the generation of altering hexagonal or hexagonal-like and cylindrical shape. Since an angle of about $141^{\circ}$ is formed between the two adjacent $\{111\}$ facets of hexagonal shape, the and compressive and tensile stresses may be caused by the growth of SiCnw. In the following process, bamboo-shaped nanowires were formed resulted from the promoted growth at the dilated region and inhibited growing at the compressive region. Further increasing the holding time, full rearrangements of atom was better achieved, and the nanowires grew into hexagonal with lower specific line energy.

\subsection{Impact of holding time on the structure order of SiCnws}

Fig.7 shows the Raman spectra and fitted Raman peaks of the SiCnws from the products with different holding times. In Fig.7a, there are two Raman peaks of 796 $\mathrm{cm}^{-1}$ (transversal optic mode of $\mathrm{SiC}, \mathrm{TO}$ ) and $968 \mathrm{~cm}^{-1}$ (longitudinal optic mode of $\mathrm{SiC}, \mathrm{LO})$ existed. The appearance of a shoulder peak located at around $765 \mathrm{~cm}^{-1}$ may be raised from the stacking faults of the SiCnws. Based on the phonon-confinement model, a smaller nanocrystal size and larger disorder will contribute to Raman scattering, thus leading to a broadening and downshift of the peaks [41]. Compared with that of the other samples, the TO and LO modes shift from about 796 to $779 \mathrm{~cm}^{-1}$ and from about 960 to $950 \mathrm{~cm}^{-1}$ for the SiCnws with a holding time of $2 \mathrm{~h}$, indicating a high structure disorder in this sample.

In the spectra of SiCnws with holding times from $1 \mathrm{~h}$ to $4 \mathrm{~h}$, the LO mode intensity decreases, gradually lowering than that of TO. According to previous reports, the LO mode intensity is always weaker than that of the TO mode, as a result of the suppression effect arising from the imperfect or disordered microstructures [42]. Whereas, the quantum confinement or defects as a result of the inner stress during the crystal growth is believed as the reason for a high LO mode. Moreover, smaller LO 
mode intensities are related to the size decrease of the SiC nanostructures. With a larger nanocrystal, the enhanced LO mode intensity will be detected [43]. Based on the above analysis, it can be inferred that the amount of structural defects reached the highest level with a holding time of $2 \mathrm{~h}$, and then decreased by prolonging the holding time. Meanwhile, as the holding time increases, the size of the SiC microcrystals was gradually decreased, as verified by the calculated grain size in Fig. 5 b.
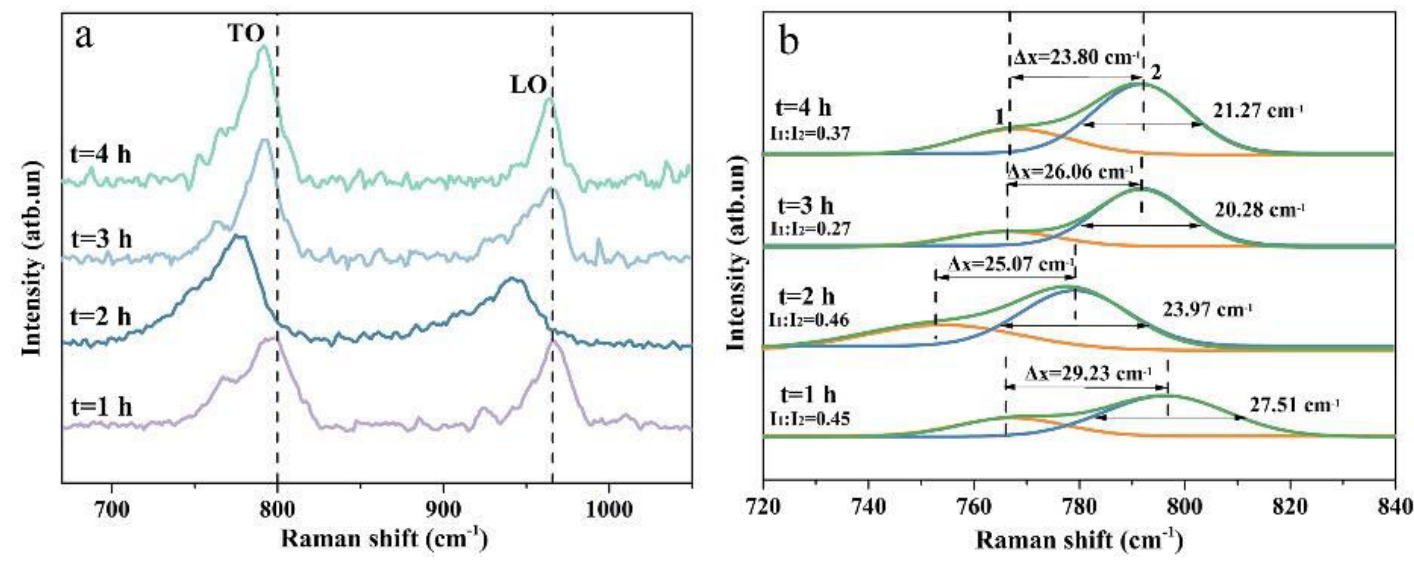

Figure 7. Raman spectra (a) and the fitted Raman peaks (b) of the SiCnw from the products with different holding times

Moreover, the ratio of the shoulder peak intensity to the one at $784 \mathrm{~cm}^{-1}$ suggests the proportion of defects versus the $\mathrm{SiC}$ crystallines. And the frequency separation between the TO peaks and its shoulders can reflect the average distance between stacking faults [44]. In Fig.7b, the intensity ratio of the shoulder peak to TO peak $\left(\mathrm{I}_{1}: \mathrm{I}_{2}\right)$ increases, and the frequency separation between these two peaks $(\Delta x)$ decreased as the holding time was extended from $1 \mathrm{~h}$ to $2 \mathrm{~h}$, indicating an increased structure disorder. Prolonging the holding time to $3 \mathrm{~h}$, decrease of the relative intensity and increase of the frequency separation suggest that prolonging the holding time would contribute to an reduced structure disorder. Whereas, the degree of the structure order decreased with an excessive holding time of $4 \mathrm{~h}$.

\subsection{Impact of silicon content on the composition and morphology of the products}

Fig. 8 presents the XRD results of the samples obtained at $1500{ }^{\circ} \mathrm{C}$ using various amounts of silicon source. As can be seen, all the samples had a composition of $\mathrm{SiC}$, $\mathrm{ZrB}_{2}$ and $\mathrm{ZrC}$. With increasing of the silicon content, peak intensity of $\mathrm{SiC}$ continually increased, and relative peak intensities of $\mathrm{ZrB}_{2} / \mathrm{ZrC}$ first decreased and 
then increased. Based on the phase compositions shown in Fig.9, $\mathrm{SiC}$ (52 wt\%), $\mathrm{ZrB}_{2}$ (33 wt $\%)$ and $\mathrm{ZrC}(13 \mathrm{wt} \%)$ were detected in the obtained product with a Si/Zr molar ratio $(\mathrm{n}(\mathrm{Si}) / \mathrm{n}(\mathrm{Zr}))$ of 6 . With the increase of the $\mathrm{n}(\mathrm{Si}) / \mathrm{n}(\mathrm{Zr})$ value, the content of $\mathrm{SiC}$ continually increased, and the relative content of $\mathrm{ZrB}_{2} / \mathrm{ZrC}$ decreased gradually on the whole. When $\mathrm{n}(\mathrm{Si}) / \mathrm{n}(\mathrm{Zr})$ reached $16, \mathrm{SiC}(78 \mathrm{wt} \%), \mathrm{ZrB}_{2}(11 \mathrm{wt} \%)$ and $\mathrm{ZrC}(11 \mathrm{wt} \%)$ were identified. By analyzing all the products, it is found that all the phase contents were lower than the theoretical $\mathrm{SiC}:\left(\mathrm{ZrB}_{2}\right.$ and $\left.\mathrm{ZrC}\right)$ weight ratio of the samples, indicating that a certain amount of gaseous reactants $(\mathrm{SiO}, \mathrm{CO})$ was escaped during the reactions. Moreover, the higher evaporation loss of $\mathrm{B}_{2} \mathrm{O}_{3}$ as a result of the refinement ceramic particles (confirmed by the following SEM analysis) contributed to the decreased amount of $\mathrm{ZrB}_{2}$. Meanwhile, the reactions between the oxides and the carbon phase to form these ceramic products became more intensive due to the same reason.

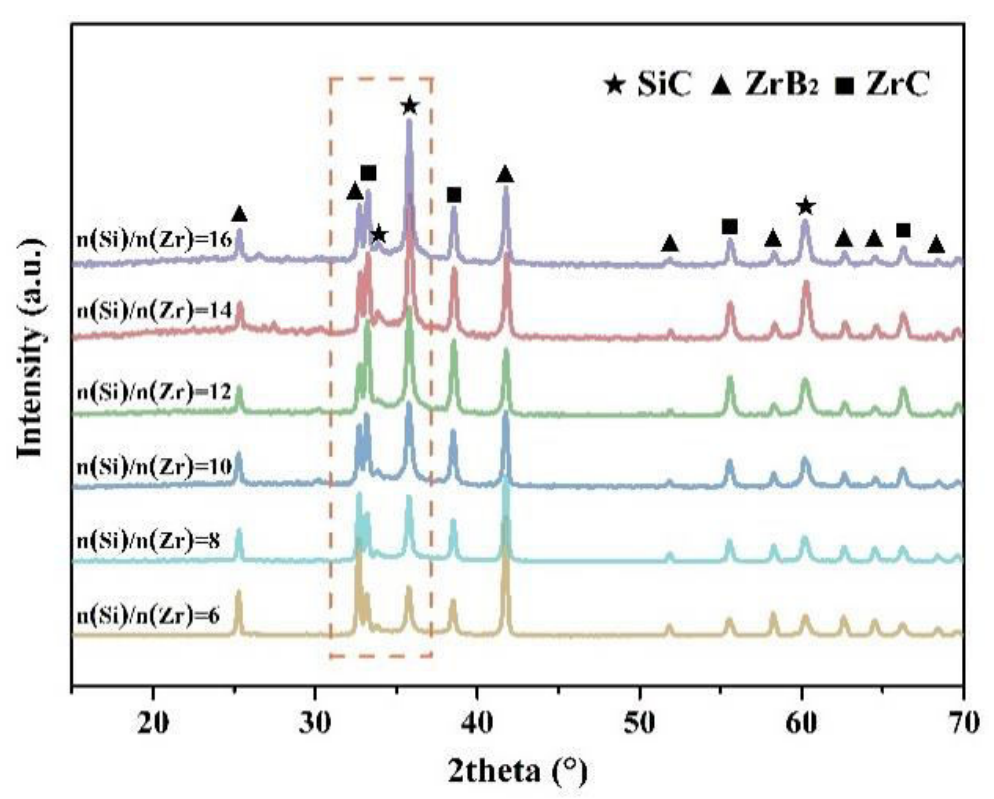

Figure 8 . XRD results of the products with different silicon contents 

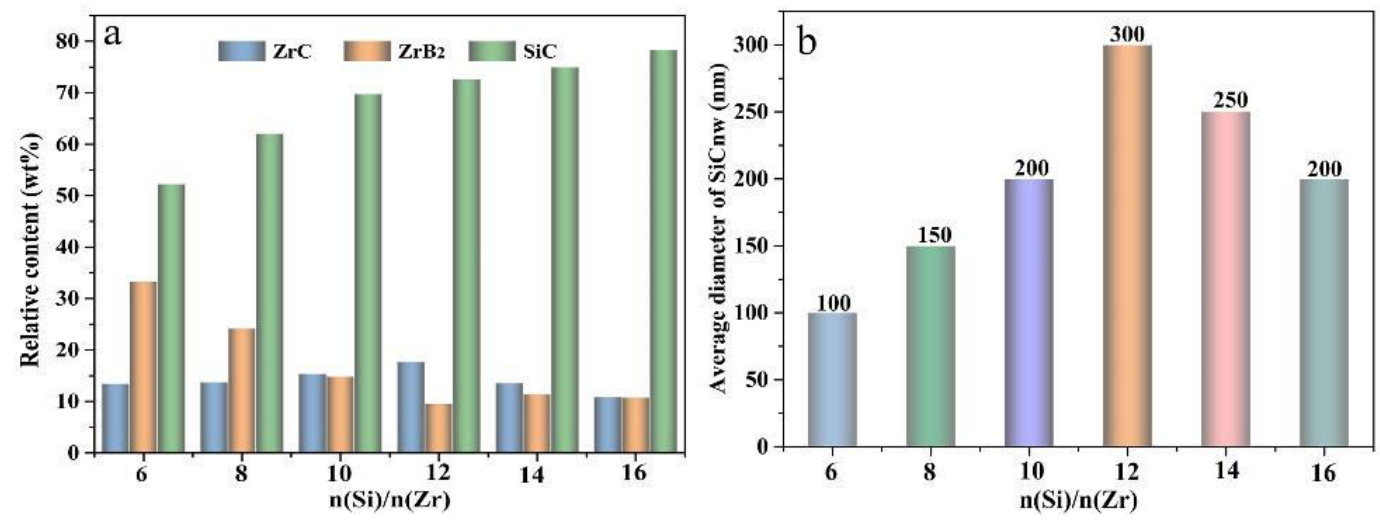

Figure 9 The content of key phases (a) and the average diameters of SiCnws (b) in the products with different silicon contents

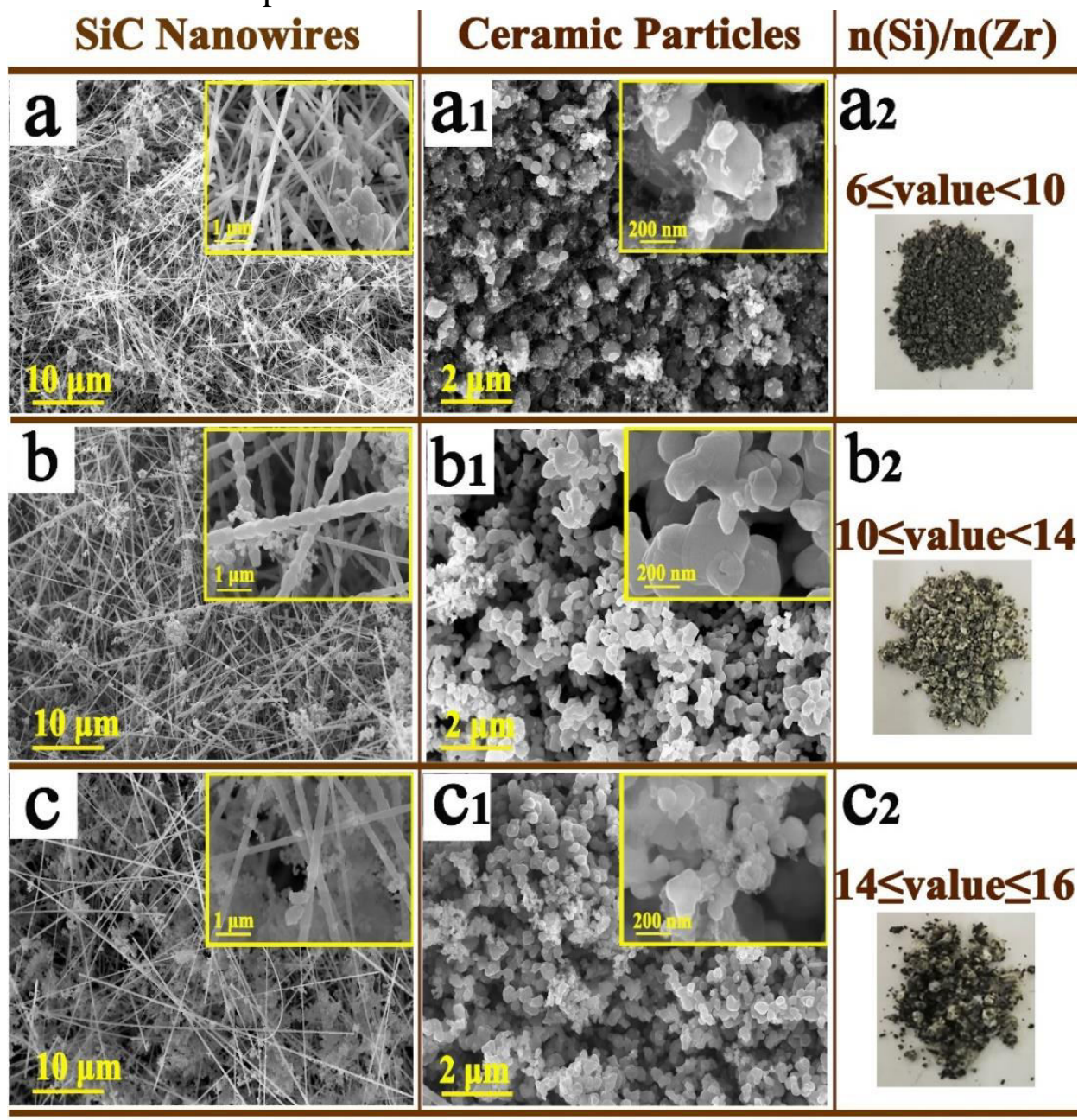

Figure 10. SEM results of the products with different silicon contents $\left(\mathrm{a}, \mathrm{a}_{1}, \mathrm{a}_{2}\right) 6 \leq \mathrm{n}(\mathrm{Si}) / \mathrm{n}(\mathrm{Zr})<10,\left(\mathrm{~b}, \mathrm{~b}_{1}, \mathrm{~b}_{2}\right) 10 \leq \mathrm{n}(\mathrm{Si}) / \mathrm{n}(\mathrm{Zr})<14,\left(\mathrm{c}, \mathrm{c}_{1}, \mathrm{c}_{2}\right)$

$$
14 \leq \mathrm{n}(\mathrm{Si}) / \mathrm{n}(\mathrm{Zr})<16
$$

Fig.10 demonstrates the SEM results of the products prepared from precursors with different silicon contents. The average diameters of SiCnws in these products were shown in Fig.9b. The amount of SiCnws grown in the product increased with increasing $\mathrm{n}(\mathrm{Si}) / \mathrm{n}(\mathrm{Zr})$ value. When the $\mathrm{n}(\mathrm{Si}) / \mathrm{n}(\mathrm{Zr})$ value reached 16 , the growth of 
nanowires was suppressed. Moreover, besides the gradually increased length of the nanowires, the average diameters of SiCnws increased first and then decreased (as seen in Fig.9b). In addition, an obvious refinement of ceramic particles, i.e. the mean particle size decreased from about $500 \mathrm{~nm}$ to around $150 \mathrm{~nm}$, can be observed, verifying the refining functions of $\mathrm{SiC}$ [45]. For the morphologies of the grown SiCnws, from the precursor with a low $n(\mathrm{Si}) / \mathrm{n}(\mathrm{Zr})$ value (Fig. 10a), only a few short but uniform SiCnws were observed due to the insufficient concentration of reactant gases. Further increasing the silicon content (Fig. 10b), the concentration of reactant gases increased, and the growth of SiCnws was supported with a higher but fluctuating gas supersaturation. Therefore, the diameter of a single SiCnw increased, and a bead-like morphology was obtained. At an excessive silicon content, the growth of SiCnws was restricted due to the excess gas supersaturation. The formation of large $\mathrm{SiC}$ crystals was favoured initially and then the SiCnws grew in the product under reduced gas supersaturation. And a bamboo-like morphology (Fig.10c) was obtained as a result of the gradually stabilized growth rate of the radical direction in the SiCnws.

\subsection{Impact of silicon content on the structure order of SiCnws}

Fig.11 presents the typical Raman spectrum of the SiCnw with different $\mathrm{n}(\mathrm{Si}) / \mathrm{n}(\mathrm{Zr})$. TO and LO modes positioned at around $784 \mathrm{~cm}^{-1}$ and $956 \mathrm{~cm}^{-1}$ were detected, and a shoulder peak appeared at the center of $756 \mathrm{~cm}^{-1}$ corresponding to the stacking faults of SiCnws. Compared with bulk SiC with narrow diffraction peaks, all the peaks of SiCnws exhibited a broadening and asymmetry characteristic, which was believed to be caused by the size confinement effects and planar faults. Moreover, an obvious red shift was observed with increasing $\mathrm{n}(\mathrm{Si}) / \mathrm{n}(\mathrm{Zr})$ value, suggesting a decreasing nanocrystal size and increasing structure disorder. Based on the analysis of fitted Raman peaks, it can be seen that the TO line shifted to lower frequencies and was broadened with the increasing $\mathrm{n}(\mathrm{Si}) / \mathrm{n}(\mathrm{Zr})$ value. Furthermore, the relative intensity of the shoulder peak to TO peak $\left(\mathrm{I}_{1}: \mathrm{I}_{2}\right)$ increased, along with the decreased frequency separation between these two peaks, i.e. a decreasing average stacking fault distance (L), verifying an increased disorder in the products with higher silicon 
content.
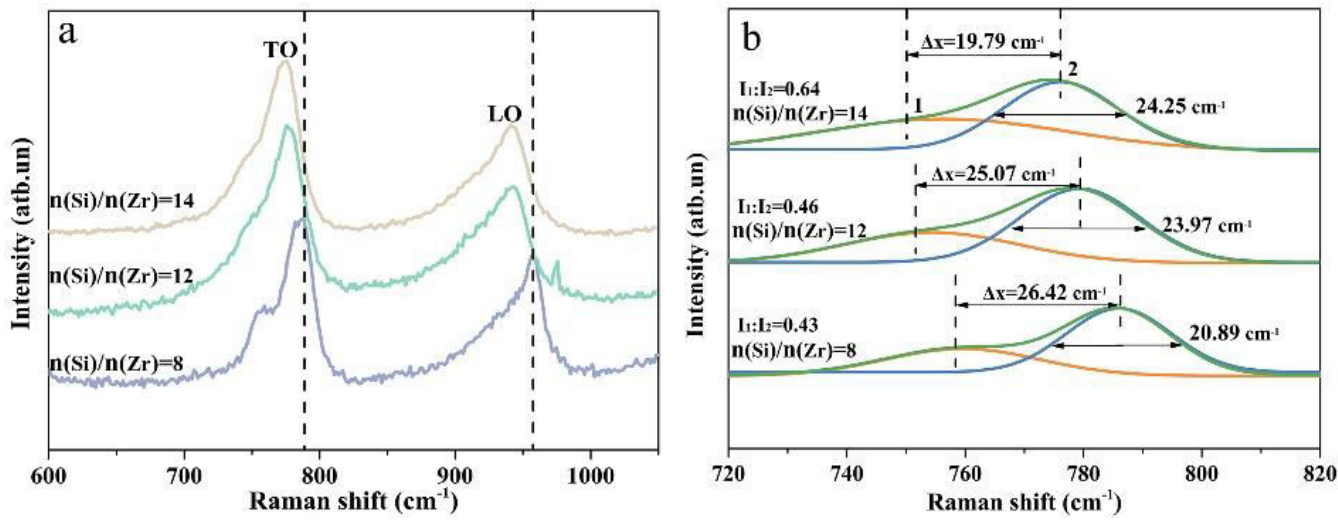

Figure 11. Raman spectra (a) and the fitted Raman peaks (b) of the SiCnw from the products with different silicon contents

\subsection{Mechanism discussion}

Fig. $12 \mathrm{a}$ shows the TEM results of the products annealed at $1500^{\circ} \mathrm{C}$ with a $\mathrm{n}(\mathrm{Si}) / \mathrm{n}(\mathrm{Zr})$ value of 12 , which reveals a uniform size distribution of $50-100 \mathrm{~nm}$. Fig.12b, 12c and 12e show the typical images of the prepared nanowires with different morphologies, and the diameters ranges from $\sim 100 \mathrm{~nm}$ to $\sim 250 \mathrm{~nm}$. The morphology of nanowires includes uniform, straight and long linear structure (Fig.12b), linear shape with a thicker node (Fig.12c), as well as short and spiral shape (Fig.12e). Moreover, no metal catalyst existed at the tip of the grown nanowires, indicating the SiCnws were formed via the typical VS mechanism. From the HRTEM in Fig. 12d, the (006) fringes are divided by about $0.254 \mathrm{~nm}$ averagely, inferring that the single crystalline SiCnw grew along the [001] direction. The SAED pattern (the inset of Fig.12c) indicates a feature of a single-crystal structure. Fig.12f reveals the existence of stacking faults and planar defects with high denisty in the spiral shape SiCnw (denoted by the white arrows in Fig. 12f). The HRTEM image of the spiral shape SiCnw also shows a growth direction of [001] (indicated by the black arrow in Fig. 12f). While, the adjacent facets form a $146.2^{\circ}$ angle, suggesting the existence of growth stress, which may be a metastable shape. Moreover, the evolution of morphologies verifies the variation of gas saturation in the growth region of SiCnws, which was determined by the competition between supplement of reaction gases $(\mathrm{SiO}$ and $\mathrm{CO}$ ) released from the carbothermal reduction reactions and the formation rate of 
$\mathrm{SiC}$. Especially, in the multiphase system, the reactions to produce $\mathrm{SiC}, \mathrm{ZrB}_{2}$ and $\mathrm{ZrC}$ are crucial to determine the morphology of SiCnw, which will be discussed in the next section. 


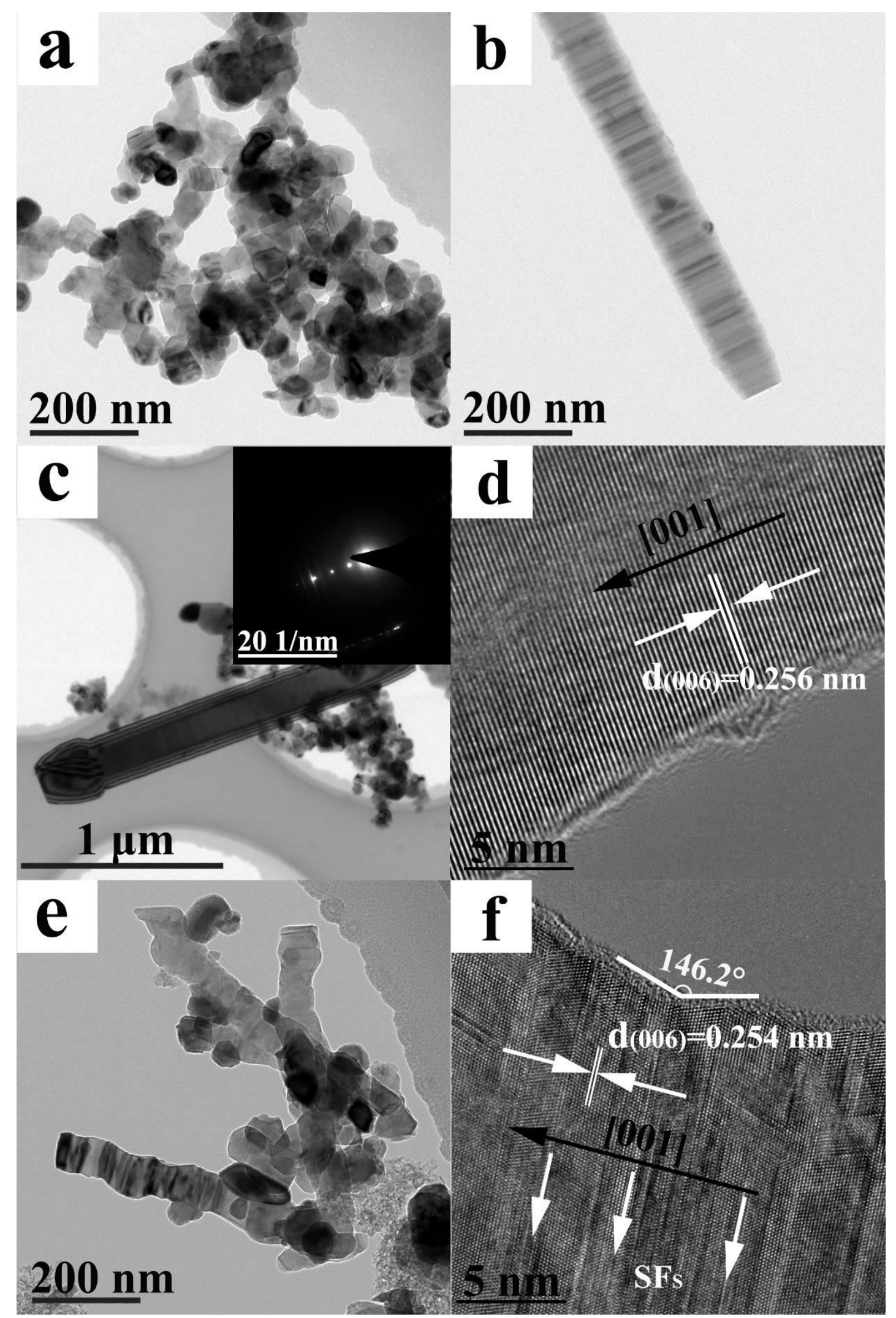

Figure 12. (a,b) TEM results of $\mathrm{ZrB}_{2}-\mathrm{ZrC}-\mathrm{SiC}$ ceramic powder, (b) TEM image of SiCnw in nano-cylinder shape, TEM (c) and HRTEM (d) results of SiCnw with fluctuating diameters and the corresponding SAED pattern (the inset of c). TEM (e) and HRTEM (f) results of SiCnw with high content of stacking faults 
The growth process of $\mathrm{ZrB}_{2}-\mathrm{ZrC}-\mathrm{SiCnw}$ is demonstrated as follows, and the influences of each factor on the morphology evolution of the SiCnws were illustrated in Fig.13. Firstly, $\mathrm{SiO}$ and $\mathrm{CO}$ gas sources were produced with the reduction of $\mathrm{SiO}_{2}$ and $\mathrm{CO}_{2}$ through reactions (1)-(3) [46]. $\mathrm{SiC}$ embryos were formed from heterogeneous nucleation by the solid-gas interaction of reaction (4), but the growth of $\mathrm{SiC}$ nanowires is determined by reaction (5) with gas-gas interaction $[47,48]$. As observed, the growth of $\mathrm{SiCnw}$ is decided by the separate partial pressure of $\mathrm{CO}$ and $\mathrm{SiO}$ vapour. At the same time, $\mathrm{ZrB}_{2}$ and $\mathrm{ZrC}$ were generated through reactions (6) and (7), respectively, accompanied by the release of gaseous $\mathrm{CO}$.

$$
\begin{aligned}
& \mathrm{SiO}_{2}(\mathrm{~s})+\mathrm{C}(\mathrm{s})=\mathrm{SiO}(\mathrm{g})+\mathrm{CO}(\mathrm{g}) \\
& \mathrm{SiO}_{2}(\mathrm{~g})+\mathrm{CO}(\mathrm{g}) \rightarrow \mathrm{SiO}(\mathrm{s})+\mathrm{CO}_{2}(\mathrm{~g}) \\
& \mathrm{CO}_{2}(\mathrm{~g})+\mathrm{C}(\mathrm{s})=2 \mathrm{CO}(\mathrm{g}) \\
& \mathrm{SiO}(\mathrm{g})+2 \mathrm{C}(\mathrm{s})=\mathrm{SiC}(\mathrm{s})+\mathrm{CO}(\mathrm{g}) \\
& \mathrm{SiO}(\mathrm{g})+3 \mathrm{CO}(\mathrm{g})=\mathrm{SiC}(\mathrm{s})+2 \mathrm{CO}_{2}(\mathrm{~g}) \\
& \mathrm{B}_{2} \mathrm{O}_{3}(\mathrm{l})+\mathrm{ZrO}_{2}(\mathrm{~s})+5 \mathrm{C}(\mathrm{s}) \rightarrow \mathrm{ZrB}_{2}(\mathrm{~s})+5 \mathrm{CO}(\mathrm{g}) \\
& \mathrm{ZrO}_{2}(\mathrm{~s})+3 \mathrm{C}(\mathrm{s}) \rightarrow \mathrm{ZrC}(\mathrm{s})+2 \mathrm{CO}(\mathrm{g})
\end{aligned}
$$

The growth of SiCnw was achieved through reaction 5, in which the $\mathrm{CO}$ gases was hard to get saturated. The irregularities along the axis of nanowires were resulted from the fluctuation in the partial pressure of gaseous $\mathrm{CO}$. Since slight variation in the gaseous will influence violently the growth of $\mathrm{SiCnws,} \mathrm{the} \mathrm{CO}$ gas generated from the bro/carbothermal reactions to form $\mathrm{ZrB}_{2} / \mathrm{ZrC}$ ceramics has an impact on the local supersaturation of the $\mathrm{SiO}$ and $\mathrm{CO}$ vapors. Below the formation temperature of $\mathrm{ZrB}_{2}$ and $\mathrm{ZrC}$ ceramics (Fig.13a), e.g. $1400{ }^{\circ} \mathrm{C}$, SiCnws in nanocylinders shape were formed since the precipitation rate of $\mathrm{SiC}$ was approximately equal to the adsorption rates of gaseous $\mathrm{CO}$ and $\mathrm{SiO}$. As shown in Fig.13b, for the sample with an $\mathrm{n}(\mathrm{Si}) / \mathrm{n}(\mathrm{Zr})$ value of $10-12$, when heat treated at $1500{ }^{\circ} \mathrm{C}$, i.e., the formation temperature of $\mathrm{ZrB}_{2}$ and $\mathrm{ZrC}$ ceramics, as the concentration of $\mathrm{CO}$ reached high supersaturation during the heating, structural defects or imperfections reached the highest level with preservation time 2 hours and the SiCnws showed a bead-like morphology. With extended holding time, the defects were reduced and the SiCnws finally grew into hexagonal 
nanocylinders. Variations in silicon source of the precursor, seen in Fig.13c, i.e. the raw material contents participated in the reactions to form $\mathrm{SiC}$, mainly caused remarkable changes in the length of nanocyclinder SiCnw, while the morphologies of the SiCnws would be more or less maintained, except for the variations in diameter fluctuation range of the single SiCnw. At higher temperature (Fig.13a), however, e.g. $1600{ }^{\circ} \mathrm{C}$, the SiCnws became energetically favorable hexagonal after the fully atom rearrangements.

\section{(a) Influence of temperature on the growth of SiCnws}
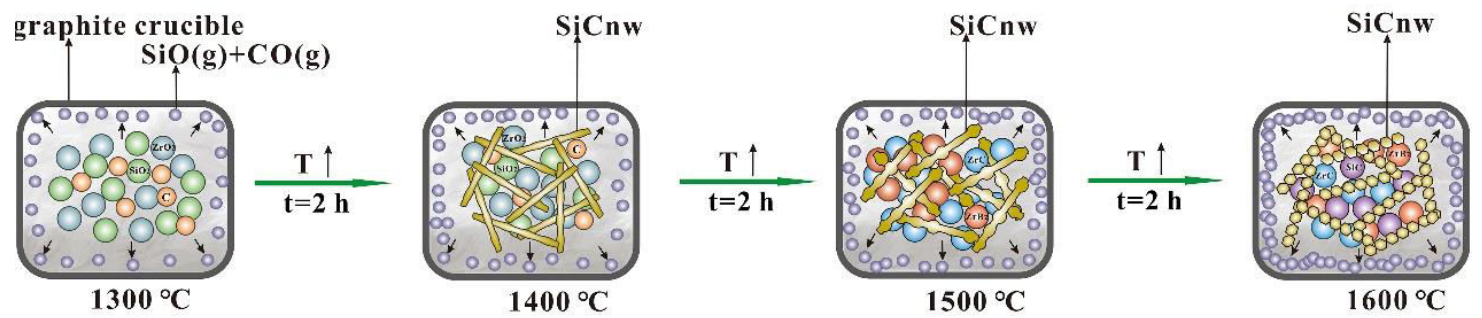

(b) Influence of holding time on the growth of SiCnws
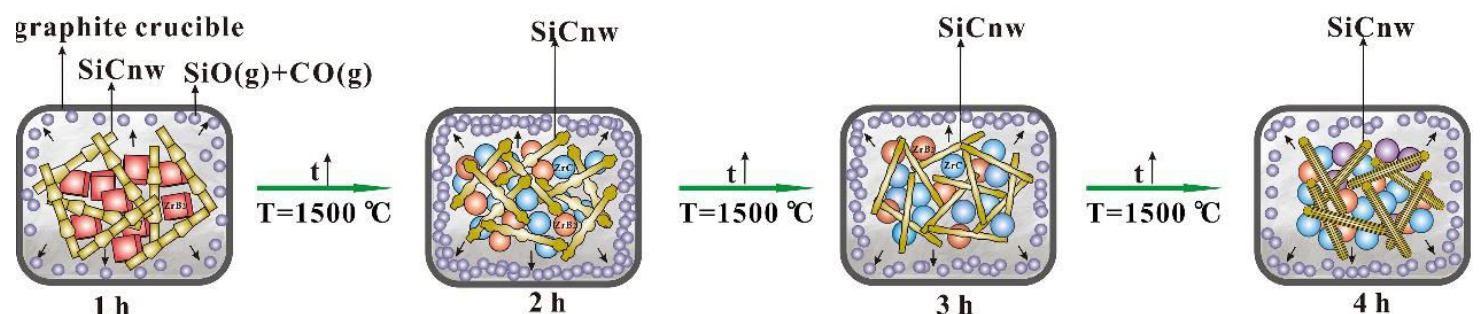

(c) Influence of $n(\mathrm{Si}) / \mathrm{n}(\mathrm{Zr})$ in the precursor on the growth of SiCnws
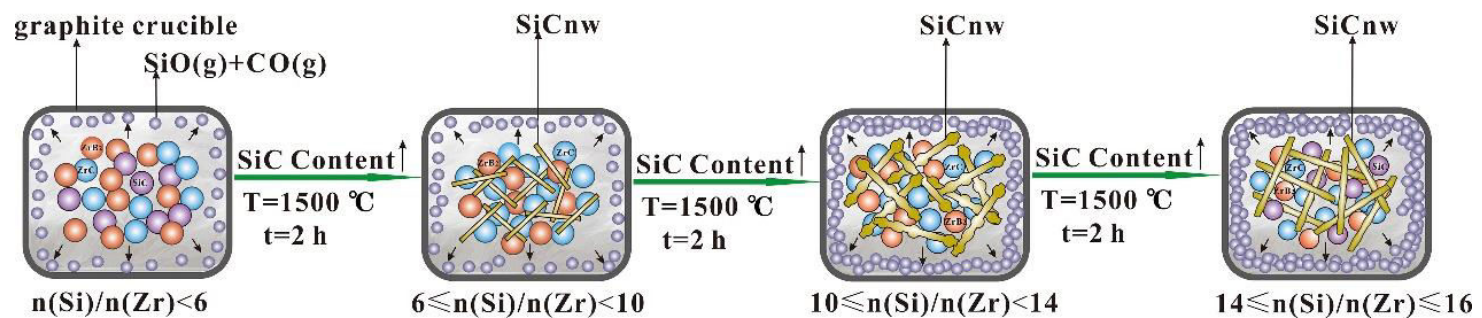

Figure 13. Schematic illustrating the influence of different factors on the morphology evolution of SiCnws

\section{Conclusions}

In summary, this work provided a simple method of in-situ fabricating uniformly dispersed SiCnws with various special morphologies in $\mathrm{ZrB}_{2}-\mathrm{ZrC}$ nanopowders was proposed. The prepared SiCnws had a diameter of varying from 100 to $400 \mathrm{~nm}$, and 
the morphologies of SiCnws included nanocylinder, bamboo-shape with tunable nodes, chain-like and hexagonal prisms, with the length of which varies from tens to hundreds of microns. The formation of $\mathrm{ZrB}_{2}-\mathrm{ZrC}-\mathrm{SiC}$ phases occured at temperatures over $1500{ }^{\circ} \mathrm{C}$. The obtained ceramic powders were in a nanoscale of about $100 \mathrm{~nm}$. The $\mathrm{CO}$ gas generated from the bro/carbothermal reactions to form $\mathrm{ZrB}_{2} / \mathrm{ZrC}$ ceramics shows an obvious impact on the local supersaturation of the $\mathrm{SiO}$ and $\mathrm{CO}$ vapors, thus leading to formation of SiCnws with specific morphologies. The in-situ grown SiCnws with specific microstructures, and the controllable morphologies opens up a new opportunity for fabricating high-performance ceramic composites.

\section{Notes}

The authors declare no competing financial interest.

\section{Acknowledgements}

This work was funded by the National Natural Science Foundation of China (grant numbers 51702194, 51702192); the Natural Science Foundation of Shaanxi Province (grant number 2018JQ5055); and the Research Startup Fund of Shaanxi University of Science and Technology (grant number 2016GBJ-09).

\section{References}

[1] Chamberlain AL, Fahrenholtz WG, Hilmas GE, et al. High-Strength Zirconium Diboride-Based Ceramics. J Am Ceram Soc 2004, 87: 1170-1172.

[2] Monteverde F, Guicciardi S, Bellosi A. Advances in microstructure and mechanical properties of zirconium diboride based ceramics. Mater Sci Eng A 2003, 346: 310-319.

[3] Sonber JK, Suri AK. Synthesis and consolidation of zirconium diboride: review. Adv Appl Ceram 2011, 110: 321-334.

[4] Miller-Oana M, Neff P, Valdez M, et al. Oxidation Behavior of Aerospace Materials in High Enthalpy Flows Using an Oxyacetylene Torch Facility. J Am 
Ceram Soc 2015, 98: 1300-1307.

[5] Tian CY, Gao D, Zhang Y, et al. Oxidation behaviour of zirconium diboride-silicon carbide ceramic composites under low oxygen partial pressure. Corros Sci 2011, 53: 3742-3746.

[6] Opeka MM, Talmy IG, Wuchina EJ, et al. Mechanical, Thermal, and Oxidation Properties of Refractory Hafnium and zirconium Compounds. J Eur Ceram Soc 1999, 19: 2405-2414.

[7] Fahrenholtz WG, Hilmas GE, Talmy IG, et al. Refractory Diborides of Zirconium and Hafnium. J Am Ceram Soc 2010, 90: 1347-1364.

[8] Tu R, Xiao B, Zhang S, et al. Mechanical, electrical and thermal properties of $\mathrm{ZrC}-\mathrm{ZrB}_{2}-\mathrm{SiC}$ ternary eutectic composites prepared by arc melting. J Eur Ceram Soc 2018, 38: 3759-3766.

[9] Xiang MY, Gu JF, Ji W, et al. Reactive Spark Plasma Sintering and Mechanical Properties of $\mathrm{ZrB}_{2}-\mathrm{SiC}-\mathrm{ZrC}$ Composites from $\mathrm{ZrC}-\mathrm{B}_{4} \mathrm{C}-\mathrm{Si}$ System. Ceram Int 2018, 44: 8417-8422.

[10] Guo SQ, Kagawa Y, Nishimura T, et al. Mechanical and physical behavior of

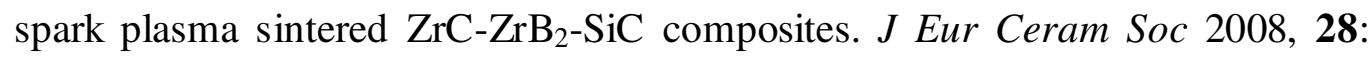
1279-1285.

[11] Wu WW, Zhang GJ, Kan YM et al. Reactive Hot Pressing of $\mathrm{ZrB}_{2}-\mathrm{SiC}-\mathrm{ZrC}$ Composites at $1600^{\circ}$ C. J Am Ceram Soc 2008, 91: 2501-2508.

[12] Zhang XH, Qu Q, Han JC, et al. Microstructural features and mechanical properties of $\mathrm{ZrB}_{2}-\mathrm{SiC}-\mathrm{ZrC}$ composites fabricated by hot pressing and reactive hot pressing. Scr Mater 2008, 59: 753-756.

[13] Bull J, White MJ, Kaufman L. Ablation resistant zirconium and hafnium ceramics. US. 1998.

[14] Monteverde F. Beneficial effects of an ultra-fine $\alpha$-SiC incorporation on the sinterability and mechanical properties of $\mathrm{ZrB}_{2}$. Appl Phys Mater Sci Process 2006, 82: 329-337.

[15] King DS, Hilmas GE, Fahrenholtz WG. Plasma arc welding of $\mathrm{ZrB}_{2}-20$ vol\% ZrC ceramics. J Eur Ceram Soc 2014, 34: 3549-3557. 
[16] $\mathrm{Xu} \mathrm{L}$, Huang CZ, Liu HL, et al. In situ synthesis of $\mathrm{ZrB}_{2}-\mathrm{ZrCx}$ ceramic tool materials toughened by elongated $\mathrm{ZrB}_{2}$ grains. Mater Des 2013, 49: 226-233.

[17] He F, Liu YS, Tian Z et al. Improvement of the strength and toughness of carbon fiber/SiC composites via chemical vapor infiltration-grown $\mathrm{SiC}$ nanowire interphases. Ceram Int 2018, 44: 2311-2319.

[18] Wang WY, Fu QG, Tan BY. Effect of in-situ grown SiC nanowires on the mechanical properties of $\mathrm{HfC}-\mathrm{ZrB}_{2}-\mathrm{SiC}$ modified $\mathrm{C} / \mathrm{C}$ composites. J Alloys Compd 2017, 726: 866-874.

[19] Huang JF, Zhou L, Cao LY, et al. Effect of the incorporation of SiC nanowire on mullite/SiC protective coating for carbon/carbon composites. Corros Sci 2016, 107: 85-95.

[20] Yang W, Araki H, Tang CC, et al. Single-Crystal SiC Nanowires with a Thin Carbon Coating for Stronger and Tougher Ceramic Composites. Adv Mater 2005, 17: $1519-1523$.

[21] Wang C, Xia L, Zhong B, et al. Fabrication and mechanical properties of carbon fibers/lithium aluminosilicate ceramic matrix composites reinforced by in-situ growth SiC nanowires. J Eur Ceram Soc 2019, 39: 4625-4633.

[22] Zhang ZF, Sha JJ, Dai JX, et al. Enhanced fracture properties of ZrB2-based composites by in-situ grown SiC nanowires. Adv Appl Ceram 2019, 118: 137-144.

[23] Zhong ZX, Yan LW, Liu L, et al. Fabrication of modified ultra high-temperature ceramic hybrid powders using in situ grown SiC nanowires. Ceram Int 2017, 43: 3462-3464.

[24] Vorotilo S, Potanin AY, Loginov PA, et al. Combustion synthesis of SiC-based ceramics reinforced by discrete carbon fibers with in situ grown $\mathrm{SiC}$ nanowires. Ceram Int 2020, 46: 7861-7870.

[25] Liu CQ, Zhang LY, Yuan XX, et al. Preparation of $\mathrm{ZrB}_{2}-\mathrm{ZrC}-\mathrm{SiC}-\mathrm{ZrO}_{2}$ nanopowders with in-situ grown homogeneously dispersed $\mathrm{SiC}$ nanowires. Mater Des 2020, 196: 109186.

[26] Hao YJ, Wagner JB, Su DS, et al. Beaded silicon carbide nanochains via 
carbothermal reduction of carbonaceous silica xerogel. Nanotechnology 2006, 17: 2870-2874.

[27] Chu YH, Li HJ, Fu QG, et al. Bamboo-shaped SiC nanowire-toughened SiC coating for oxidation protection of C/C composites. Corros Sci 2013, 70: 11-16.

[28] Tao XY, Liu J, Koley G, et al. B/SiOx Nanonecklace Reinforced Nanocomposites by Unique Mechanical Interlocking Mechanism. Adv Mater 2008, 20: 4091-4096.

[29] Huang ZH, Liu HT, Chen K, et al. Synthesis and formation mechanism of twinned SiC nanowires made by a catalyst-free thermal chemical vapour deposition method. RSC Adv 2014, 4: 18360-18364.

[30] Xin LP, Shi Q, Chen JJ, et al. Morphological evolution of one-dimensional SiC nanomaterials controlled by sol-gel carbothermal reduction. Mater Charact 2012, 65: $55-61$.

[31] Jaworska L, Panasiuk J, Putyra P, et al. The influence of powder characteristics on the sintering behaviour and impurity content of spark-plasma-sintered zirconium. Int J Refract Met Hard Mater 2019, 82: 259-267.

[32] Liang MS, Li F, Ma XF, et al. Syntheses of ZrC-SiC nanopowder via sol-gel method. Ceram Int 2016, 42: 1345-1351.

[33] Gleiter H. Nanostructured materials: state of the art and perspectives. Nanostructured Mater 1995, 6: 3-14.

[34] Sawaguchi A, Toda K, Niihara K. Mechanical and Electrical Properties of Silicon Nitride-Silicon Carbide Nanocomposite Material. J Am Ceram Soc 1991, 74: 1142-1144.

[35] Ionescu E, Kleebe HJ, Riedel R. Silicon-containing polymer-derived ceramic nanocomposites (PDC-NCs): preparative approaches and properties. Chem Soc Rev 2012, 41: 5032-5052.

[36] Venugopal S, Boakye EE, Paul A, et al. Sol-Gel Synthesis and Formation Mechanism of Ultrahigh Temperature Ceramic: $\mathrm{HfB}_{2}$. J Am Ceram Soc 2014, 97: 92-99.

[37] Ang C, Seeber A, Wang K, et al. Modification of $\mathrm{ZrB}_{2}$ powders by a sol-gel $\mathrm{ZrC}$ 
precursor-A new approach for ultra high temperature ceramic composites. $J$ Asian Ceram Soc 2013, 1: 77-85.

[38] Dolle M, Gosset D, Bogicevic C, et al. Synthesis of nanosized zirconium carbide by a sol-gel route. J Eur Ceram Soc 2007, 27: 2061-2067.

[39] Zhang Y, Li RX, Jiang YS, et al. Morphology evolution of $\mathrm{ZrB}_{2}$ nanoparticles synthesized by sol-gel method. J Solid State Chem 2011, 184: 2047-2052.

[40] Wu RB, Li BS, Gao MX, et al. Tuning the morphologies of SiC nanowires via the control of growth temperature, and their photoluminescence properties. Nanotechnology 2008, 19: 35602-35602.

[41] Campbell IH, Fauchet PM. The effects of microcrystal size and shape on the one phonon Raman spectra of crystalline semiconductors. Solid State Commun 1986, 58: $739-741$.

[42] Sasaki Y, Nishina Y, Sato M, et al. Raman study of SiC fibres made from polycarbosilane. J Mater Sci 1987, 22: 443-448.

[43] Liu LZ, Wang J, Wu XL, et al. Longitudinal optical phonon-plasmon coupling in luminescent 3C-SiC nanocrystal films. Opt Lett 2010, 35: 4024-4026.

[44] Wieligor M, Wang YJ, Zerda TW. Raman spectra of silicon carbide small particles and nanowires. J Phys Condens Matter 2005, 17: 2387-2395.

[45] Liu CQ, Chang XJ, Wu YT, et al. Effect of SiC content on microstructure evolution of $\mathrm{ZrB}_{2}-\mathrm{ZrC}-\mathrm{SiC}$ ceramic in sol-gel process. Vacuum 2020, 177: 109430.

[46] Alex AS, Bhuvaneswari S, Chandran SC, et al. Microstructure and phase evolution in pyrolysed short fibre reinforced polymethylsilsesquioxane-phenolic interpenetrating networks. J Anal Appl Pyrolysis 2018, 129: 241-247.

[47] $\mathrm{Wu}$ ZH, Zheng HK, Zhang GL, et al. Synthesis of diameter-fluctuating silicon carbide nanowires for excellent microwave absorption. Mater Chem Phys 2020, 244: 122648.

[48] Shen ZZ, Chen JH, Li B, et al. Tunable fabrication and photoluminescence property of SiC nanowires with different microstructures. Appl Surf Sci 2020, 506: 144979. 